\title{
LA EFICACIA DEL PACTO ARBITRAL EN ALGUNOS CONTRATOS DE SEGURO. UNA REVISIÓN DESDE LA JURISPRUDENCIA"
}

\author{
The effectiveness of the arbitral pact in some \\ insurance contracts. A review from jurisprudence
}

Dionisio Araujo Angulo**

\begin{abstract}
Resumen
Habiéndose pactado cláusula arbitral en algunos contratos de seguros se han presentado decisiones judiciales contradictorias, unas restándole eficacia y otras apuntalándola, cuando con ocasión de llamamientos en garantía o en el ejercicio de potestades exorbitantes por autoridades públicas se suscita controversia respecto de la jurisdicción competente para conocer de ellas, en especial al revisar relaciones surgidas en contratos de seguro de responsabilidad civil y en seguros de cumplimiento de contratos estatales.

Este artículo, al revisar distintas providencias judiciales contradictorias, pretende presentar algunas conclusiones respecto de cuál de los fundamentos de las decisiones analizadas debe prevalecer.
\end{abstract}

* Artículo inédito.

Para citar el artículo: ARAUJO ANGULO, Dionisio. La eficacia del pacto arbitral en algunos contratos de seguro. Una revisión desde la jurisprudencia. Revista del Instituto Colombiano de Derecho Procesal. No. 47 Enero - Junio. 2018, pp. 219-243.

Recibido: 24 de febrero de 2018 - Aprobado: 25 de julio de 2018.

** Abogado de la Universidad Javeriana con especialización de la misma Universidad en derecho de seguros, ha sido asesor jurídico de la Dirección de Coldeportes, Director de Defensa Judicial de la Nación del Ministerio del Interior y de Justicia, encargado de la oficina jurídica y de la Secretaría General del mismo Ministerio, Cónsul General de Colombia en Roma, Italia Agente del Estado colombiano ante la Corte Interamericana de Derechos Humanos, Director ad hoc de la Dirección Nacional de Estupefacientes y Superintendente (e) de Notariado y Registro. Abogado litigante y asesor en derecho comercial, administrativo y de seguros por más de quince años. 
La eficacia del pacto arbitral en algunos contratos de seguro

Palabras clave: eficacia, pacto arbitral, contratos de seguros, decisiones judiciales, revisión.

\begin{abstract}
Having agreed arbitration clause in some insurance contracts have been contradictory judicial decisions, some subtracting effectiveness and other endorsed, when on the occasion of appeals in guarantee or in the exercise of exorbitant powers by public authorities there is controversy regarding the jurisdiction to hear of them, especially when reviewing relationships arising in civil liability insurance contracts and state contract compliance insurance.

This article, when reviewing different contradictory judicial decisions, intends to present some conclusions regarding which of the fundamentals of the decisions analyzed should prevail.
\end{abstract}

Keywords: effectiveness, arbitration agreement, insurance contracts, judicial decisions, review.

\title{
Introducción
}

Es usual que en determinados contratos de seguro se pacte cláusula arbitral para que sea esta particular justicia la que resuelva los conflictos nacidos con ocasión o por cuenta de un contrato de seguro, que incluye por supuesto la determinación de la ocurrencia del siniestro y la cuantía de la pérdida, causales exonerativas y obligación de pago de la indemnización, lo que de suyo no es ni novedoso ni supone problemas procedimentales o conceptuales.

Sin embargo cuando el seguro tiene por objeto cubrir riesgos del tomador o asegurado en favor de terceras personas como beneficiarias de la prestación, como en el caso de los seguros de responsabilidad civil bien porque se vincule directamente al asegurador por el beneficiario en ejercicio de la acción directa o bien porque el asegurado sea demandado y pretenda vincular al proceso a su asegurador a través de un llamamiento en garantía, o como en el caso de los seguros de cumplimiento, la existencia de cláusulas compromisorias ha permitido decisiones judiciales contradictorias respecto de la eficacia de dicho pacto, unas negándola y señalando que la competente para resolver tales controversias es la jurisdicción ordinaria, otras validándola negando la competencia de la justicia ordinaria para resolverlas.

Parte importante de la doctrina ${ }^{1}$ ha fundado la validez del pacto arbitral, y de sus efectos y consecuencias, en la teoría general del acto jurídico y del derecho

1 RAMÍREZ GÓMEZ, Jorge Alberto. La vinculación de sujetos no signatarios a los efectos del pacto arbitral. Ed. Universidad Externado de Colombia, Bogotá, Colombia. 2017. 
de obligaciones, esto es en la expresión del consentimiento libre y espontáneo de obligarse a resolver una disputa actual o eventual a través de un tribunal de arbitramento como fuente de la validez y eficacia del laudo arbitral.

Como postulado general bien sentado tiene la jurisprudencia que ante la existencia de pacto arbitral la jurisdicción ordinaria cede su competencia, sin embargo, como se verá más adelante, con ocasión del estudio de la eficacia de dicho pacto en contratos de seguro, en especial de seguros responsabilidad civil y de seguros de cumplimiento de contrato estatal, algunas decisiones judiciales han desconocido tal efecto resolviendo mantener la competencia cuando les ha sido propuesta la excepción correspondiente.

Considerando que en los contratos tipo, como en los de seguros de responsabilidad civil, el tema de la cláusula arbitral no es de los que usualmente se discute entre las partes, como si lo son las coberturas, valores asegurados, sub límites por algunas tipologías de daños y exclusiones, el tema del consentimiento como fuente obligacional del pacto arbitral para justificar la exclusión de un determinado conflicto del conocimiento de la justicia ordinaria podría ser considerado como argumento para negarle eficacia, que será uno de los temas que veremos en la revisión jurisprudencial que será el objeto de este estudio.

Este artículo se dirige a i) revisar la eficacia del pacto arbitral en dos contratos de seguro, el de responsabilidad civil y el de cumplimiento a favor de entidades estatales, con ocasión de algunas decisiones judiciales que le han restado eficacia, a la luz de la jurisprudencia reiterada de nuestras altas corporaciones sobre la incompetencia que en la jurisdicción ordinaria se produce cuando se ha acordado pacto arbitral; ii) a revisar si tales decisiones que niegan eficacia se fundan en consideraciones subjetivas respecto del consentimiento de las personas para vincular sus diferencias a la decisión de un tribunal de arbitramento -rationae personae- y a presentar algunas conclusiones correspondientes, o iii) en otras razones de índole procesal.

Se busca con este documento aportar elementos de juicio que sirvan a los operadores judiciales cuando se enfrentes a la existencia de pactos arbitrales en los contratos de seguro que serán objeto de estudio, evitando decisiones contradictorias y que desarrollen los postulados de eficiencia, eficacia y economía procesal, dándole prevalencia a la voluntad de las partes cuando se haya decidido por la justicia arbitral.

Para lograr el propósito perseguido se presentará un marco conceptual que recuerde el efecto del pacto arbitral sobre la competencia natural de la jurisdicción ordinaria; pasaré por la revisión de la figura del llamamiento en garantía como forma de vincular a una compañía aseguradora a un proceso ya en marcha, así como de la posibilidad de que sea citado directamente por el eventual beneficiario de la prestación en seguros de responsabilidad civil, cuando en tal 
La eficacia del pacto arbitral en algunos contratos de seguro

contrato se ha incluido un pacto arbitral; para finalmente hacer una revisión y análisis de variadas decisiones judiciales de distintos órganos y niveles de la jurisdicción ordinaria, a la luz de conceptos y normas que determinan el efecto procesal consecuencia del pacto arbitral, teniendo siempre como referente la jurisprudencia de nuestras altas corporaciones de justicia en torno al asunto.

El pacto arbitral. Efecto principal

De conformidad con lo señalado en la Ley 1563 de 2012, el pacto arbitral "es un negocio jurídico por virtud del cual las partes someten o se obligan a someter a arbitraje controversias que hayan surgido o puedan surgir entre ellas", e "implica la renuncia de las partes a hacer valer sus pretensiones ante los jueces.", "...puede consistir en un compromiso o en una cláusula compromisoria."

Cuando las partes en el marco de un contrato ex ante acuerdan que si entre ellas se suscita una controversia la deferirán para su resolución a un tribunal de arbitramento - cláusula compromisoria-, o ya en presencia de un conflicto irresuelto deciden sustraer su definición de la justicia ordinaria para sujetarla a la arbitral - compromiso-, al amparo de lo previsto en el artículo 116 de la Constitución están válidamente habilitando a quienes serán sus árbitros para que con altura de cosa juzgada decidan definitivamente un asunto para el que en principio estaría destinada la jurisdicción estatal, tal y como lo ha definido la Corte Constitucional ${ }^{2}$ al señalar

"... que el arbitramento es un mecanismo "en virtud del cual las partes en conflicto deciden someter sus diferencias a la decisión de un tercero, aceptando anticipadamente sujetarse a lo que alli se adopte". Este procedimiento supone otorgar jurisdicción a favor de un particular, respecto de un litigio específico, quien queda investido de la facultad temporal de resolverlo con carácter definitivo y obligatorio mediante una decisión denominada laudo arbitral. El ejercicio de la facultad de administrar justicia denota su naturaleza eminentemente jurisdiccional y marca el carácter procesal de esta figura ya que como lo ha explicado esta Corte "se trata de un proceso, puesto que los particulares, al administrar justicia como árbitros, deben materializar, dentro de la lógica propia del arbitraje y atendiendo a sus especificidades, los derechos fundamentales al debido proceso, de defensa y de acceso a la administración de justicia, respetando el marco trazado por el legislador. Por ello, el arbitramento se concibe como un proceso que garantiza los derechos de las partes enfrentadas, mediante un conjunto de etapas y oportunidades para discutir argumentos, valorar pruebas, controvertir la posición de la otra parte e incluso controlar las decisiones de los árbitros".

2 COLOMBIA, CORTE CONSTITUCIONAL, sentencia C-170 /2014. MP. Alberto Rojas Ríos, 19 de marzo de 2014. 
Esta habilitación supone, como dice la Corte, otorgar jurisdicción a los particulares que en forma de árbitros resolverán las cuestiones a ellos sometidas conforme el pacto arbitral, lo que a su vez implica deshabilitar la competencia de la jurisdicción ordinaria que sin el pacto sería la habilitada para conocer y decidir sobre tal controversia.

Como bien lo ha señalado parte de la Doctrina $^{3}$, la suscripción de un pacto arbitral al suponer la renuncia a la jurisdicción ordinaria, implica una obligación de no hacer consistente en no ventilar una controversia ante los jueces ordinarios, y por ello la legislación positiva ha previsto como excepción previa la existencia de pacto arbitral.

Como señaló Julio Benetti Salgar", "[o]tro efecto del pacto arbitral, el más importante, es de carácter procesal y consiste en sustraer el conflicto del conocimiento de la justicia ordinaria..."; por ello tanto la Ley 1563 de 2012, contentiva del Estatuto de Arbitraje Nacional e Internacional, como el Código General del Proceso contienen disposiciones que indican tal atribución exclusiva de competencia a la justicia arbitral, que concomitantemente implica la pérdida de competencia de la justicia ordinaria.

Dice el artículo $3^{\circ}$ de la Ley 1563:

"ARTÍCULO 3o. PACTO ARBITRAL. El pacto arbitral es un negocio jurídico por virtud del cual las partes someten o se obligan a someter a arbitraje controversias que hayan surgido o puedan surgir entre ellas.

El pacto arbitral implica la renuncia de las partes a hacer valer sus pretensiones ante los jueces. El pacto arbitral puede consistir en un compromiso o en una cláusula compromisoria.

En el pacto arbitral las partes indicarán la naturaleza del laudo. Si nada se estipula al respecto, este se proferirá en derecho.

PARÁGRAFO. Si en el término de traslado de la demanda, o de su contestación, o de las excepciones previas, una parte invoca la existencia de pacto arbitral y la otra no la niega expresamente, ante los jueces o el tribunal de arbitraje, se entiende válidamente probada la existencia de pacto arbitral".

A su vez el Código General del Proceso permite advertir la existencia de la causal de incompetencia derivada del pacto arbitral acordado entre las partes en conflicto desde la propia contestación de la demanda, a través de la excepción

3 MANCIAUX, Sébastien. "El orden público y el arbitraje." Editorial Universidad del Rosario, Bogotá, Colombia. 2017.

4 BENETTI SALGAR, Julio “El arbitraje en el Derecho colombiano." Ed Temis, Bogotá, Colombia. 1994. 
La eficacia del pacto arbitral en algunos contratos de seguro

previa autorizada expresamente en el numeral $2^{\circ}$ del artículo 100 , con el efecto señalado en el inciso cuarto del numeral $2^{\circ}$ del artículo 101 al señalar:

"Si prospera la de compromiso o cláusula compromisoria, se decretará la terminación del proceso y se devolverá al demandante la demanda con sus anexos."

También reconoce que tramitar un proceso sin competencia es causal de nulidad conforme indica el numeral $1^{\circ}$ del artículo 133 del CGP, falta de competencia que es la consecuencia de la existencia de pacto arbitral conforme decisión reciente de la Corte Suprema de Justicia que se transcribirá más adelante.

Podría afirmarse, junto con algunos comentaristas ${ }^{5}$, que la existencia de un pacto arbitral es asunto que atañe al orden público y en consecuencia el respeto por sus efectos y consecuencias interesa a todos y no sólo a las partes involucradas en el conflicto.

\section{La existencia de pacto arbitral el contratos de seguro de responsabilidad civil. Llamamiento en garantía y acción directa del perjudicado}

De tiempo atrás está prevista en las legislaciones procesales la posibilidad de que se resuelvan en el seno de un proceso judicial relaciones jurídicas en principio ajenas y extrañas a las que originalmente abrieron la puerta a la jurisdicción, fundada en razones de eficiencia, eficacia y economía procesal. En la nueva terminología procesal asumida por el Código General del Proceso tal figura habilitante de competencia se denomina exclusivamente llamamiento en garantía.

Sobre tal figura hay ya decantada jurisprudencia y doctrina que la identifica y delimita, baste como mejor explicación de ella citar a la Corte Suprema de Justicia quien sobre ella, entre otras muchas decisiones, ha dicho:

"El llamamiento en garantía es un instrumento procesal por el cual se provoca la comparecencia forzosa de un tercero a un proceso en curso, intervención que tiene su germen en la citación que le formula una de las partes en dicha

$5 \quad$ RACINE, Jean Baptiste. "Las normas que estructuran el orden público en el arbitraje comercial internacional” artículo en "El orden público y el arbitraje." Editorial Universidad del Rosario, Bogotá, Colombia. 2017 "El árbitro aplica un orden público estatal para respetar la voluntad de las partes o para asegurar la eficacia de la sentencia y también puede hacerlo en nombre del ideal de la justicia (cuando el orden público en cuestión refleja un valor de justicia que el árbitro considera importante)." 
contienda, con fundamento en la relación de garantía de naturaleza personal entre ellos existente, que le confiere el derecho de exigirle que corra con las consecuencias perjudiciales que deba soportar en el evento de resultar vencida en el juicio, de ahí que lo llame a afrontar la pretensión de regreso que introduce para que sea considerada in eventum, es decir, en el caso de perder el pleito. En otras palabras, lo trae al proceso para que se resuelva sobre la obligación legal o contractual que tiene de reembolsarle o indemnizarle las pérdidas económicas que experimente en el caso de un sentenciamiento adverso.

Con el llamamiento en garantía, tiene dicho la Corte, se suscita un "evento de acoplamiento o reunión de una causa litigiosa principal con otra de garantía que le es colateral, dando lugar a una modalidad acumulativa cuyos alcances precisa el art. 57 del C. de P.C." (Sent. 064 -3 del 12 de Julio de 1995), que conjuga dos relaciones materiales distintas. Por un lado, la que une al demandante con el demandado, y por el otro, la que liga al demandado con el llamado: "la del demandante contra el demandado, en procura de que este sea condenado de acuerdo con las pretensiones de la demanda contra él dirigida; y la del demandado contra el llamado en garantía a fin de que éste lo indemnice o le reembolse el monto de la condena que sufriere" (Cas. Civ. del 28 de septiembre de 1977)."

Como se desprende de las palabras de la Corte recién citadas, el llamamiento en garantía permite, a través del factor de conexidad, decidir en una sola sentencia el objeto de lo que en principio debieron ser dos controversias o conflictos, el primigenio que existe entre demandante y demandado, y en caso de que este último sea condenado, el formado por el vínculo jurídico sustancial existente entre el llamante y el llamado, permitiendo, entonces, que por virtud de la facultad que la ley ofrece al demandante o al demandado que es quien por lo general hace uso de esta facultad, se decida sobre una pretensión específica contra quien, sin necesidad de haber sido demandado directo, sea citado al proceso producto del llamamiento, con el fin de que se dilucide la relación sustancial que pueda existir entre él y quien lo cita.

Corresponde al juez, por tanto, determinar si la reclamación que se le hace para salir al cubrimiento de la indemnización que se le imponga al demandado en el proceso, es viable o no, de acuerdo con el derecho legal o contractual que se disputa. En palabras de la Corte Suprema, esta figura "[p]ermite convocar en principio a una persona diferente a las partes inicialmente trabadas en la

6 CORTE SUPREMA DE JUSTICIA, SALA DE CASACIÓN CIVIL, sentencia de 15 de diciembre de 2006 dentro del expediente No. 52001-31-03-004-2000-00276-01. MP. Jaime Alberto Arrubla Paucar. 
La eficacia del pacto arbitral en algunos contratos de seguro

relación procesal (demandante y demandado), con fundamento en una relación sustancial (por ministerio de la ley) o por virtud de una relación contractual, existente entre el llamante y el llamado para que éste, responda de acuerdo a ese vínculo jurídico, de modo que el demandado llamante se libre de los eventuales efectos adversos que pueda acarrearle el litigio. Por tanto, es la relación material la que justifica trasladar los efectos adversos de la sentencia de una parte participante en la disputa al ahora citado, razón por la cual se acerca procesalmente a la denuncia del pleito. Por supuesto, se le llama, por múltiples razones, entre ellas, por economía procesal y ante todo, para darle la oportunidad de ejercer su derecho de defensa, en la pretensión de reembolso o "revérsica" que le formula la parte convocante. Pero también puede surtirse, llamando a la coparte, como en éste caso."

Claro resulta que en virtud del llamamiento en garantía el juez de una causa es excepcionalmente habilitado para conocer en el seno de ella de otra que en principio le es extraña, de la que es parte quien en la primera controversia normalmente tiene el carácter de parte demandada, y que si no se permitiese tal tipo de acumulación procesal el fondo de ella debería ser estudiado y resuelto en proceso distinto.

Ahora bien, como se ha señalado es posible que tratándose de un contrato de seguros se haya pactado una cláusula arbitral en cuya virtud sus partes hubieran habilitado a la justicia arbitral para que en modo exclusivo resolviera los conflictos que se presentasen al interior de dicha relación negocial, existiendo o i) habilitación legal que se le reconoce en contratos de responsabilidad civil a los perjudicados directos de la conducta del asegurado para demandar a la compañía aseguradora, o ii) existiendo la posibilidad de que el asegurado demandado por su presunto perjudicado vincule al proceso primigenio a su compañía aseguradora vía el llamamiento en garantía.

Siendo posible, además, conforme enseña el profesor Hernán Fabio López ${ }^{8}$, que la excepción correspondiente a la existencia del pacto arbitral pudiera ser presentada aún frente al perjudicado y beneficiario de la prestación asegurada. Dijo el profesor "Naturalmente, en este caso la aseguradora puede proponer al beneficiario las mismas excepciones que ha podido formular en contra del asegurado en la hipótesis de que este lo hubiere demandado tal como lo prevé el inciso segundo del artículo $1077 \mathrm{del} \mathrm{C.} \mathrm{de} \mathrm{Co."}$

7 CORTE SUPREMA DE JUSTICIA, SALA DE CASACIÓN CIVIL, expediente SC58852016, sentencia del 6 de mayo de 2016, MP. Luis Armando Tolosa Villabona.

8 LÓPEZ BLANCO, Hernán Fabio. “Comentarios al Contrato de Seguro”. Dupré Editores, Bogotá Colombia. 2a. Edición, 1993. 
Dionisio Araujo Angulo

\section{El pacto arbitral frente a un llamamiento en garantía. ¿Es incompetente el juez ordinario?}

Habiéndose inter partes deferido a la justicia arbitral la resolución de controversias que puedan darse con ocasión de la existencia, celebración, ejecución o terminación de un contrato de seguro, sin perjuicio de que la habilitación arbitral sea limitada a ciertos asuntos específicos de la relación negocial, en presencia de un conflicto comprendido dentro del ámbito de habilitación dado por las partes a la justicia arbitral se sigue de ello la principal consecuencia que se ha definido para dicha justicia particular, la incompetencia de la justicia ordinaria, que no falta de jurisdicción como recientemente ha aclarado la Corte Suprema ${ }^{9}$, al decir:

"Pero es evidente que quien no demandó no puede verse forzado a tener que demandar por vía arbitral. Debe reconocerse que esa excepción -que entre nosotros tiene existencia propia pues la prevé explícitamente el numeral $3^{\circ}$ del artículo 97 del c.p.c y permanece tal consagración en el código general del proceso (art. 100) - de ser ilegalmente denegada, afectaría gravemente el pacto que es ley para las partes, sin contar, la que reclama su cumplimiento, con ningún otro medio de impugnación ordinario. Estima la Corte, en consecuencia, que a pesar de la preindicada autonomía o tipicidad de la excepción previa, ella en sí misma engloba un fenómeno de falta de competencia objetiva ratione materia, pues atiende justamente al contenido de la relación sustancial subyacente en la controversia y su subsunción en el acuerdo previo que vincula a las partes (cláusula compromisoria), lo que por vía de la causal quinta puede ventilarse en casación. En ese sentido menester es destacar que nuestro ordenamiento procesal, al consagrar la existencia de cláusula compromisoria o compromiso como excepción autónoma está un paso adelante de otras de Iberoamérica que oscilan entre la falta de competencia o la falta de jurisdicción que deben ser propuestas a la primera oportunidad."

A la luz de lo señalado por la Corte Suprema aparecería clara la incompetencia de la justicia ordinaria cuando las partes han deferido a la arbitral la solución de sus controversias conforme a lo estipulado en el pacto arbitral, y de ella se seguiría la nulidad consecuente si se actuase ante la ordinaria luego de reconocida la existencia de pacto arbitral.

9 CORTE SUPREMA DE JUSTICIA, SALA DE CASACIÓN CIVIL, Sentencia de 9 de mayo de 2017, Expediente $n^{\circ}$ 11001-31-03-019-2008-00247-01. MP. Margarita Cabello Blanco. 
Esta posición aparentemente desdeciría otras decisiones de la propia Corte ${ }^{10}$ que han señalado como tácitamente desistido el pacto arbitral cuando no se alega como previa la excepción, sin que por supuesto el objeto de este escrito alcance para recoger esa importante discusión doctrinal.

En atención al propósito de este escrito, una primera pregunta que surge es si vinculada una relación contractual en que hay pacto arbitral a un proceso en curso por vía de un llamamiento en garantía la incompetencia del juez primigenio es absoluta, o hay casos en que se puede desconocer el principio de inhabilitación voluntaria de la competencia ordinaria. Dicho de otro modo, se indagará en estas líneas si el pacto arbitral es siempre oponible en el trámite de un llamamiento en garantía o hay casos en que no y cuáles son.

Para responder esa pregunta se revisarán algunos pronunciamientos judiciales de distintos órdenes a la luz de la regla general de incompetencia planteada reiteradamente por la Corte Suprema de Justicia y el Consejo de Estado, para finalmente revisar tangencialmente la incidencia del pacto arbitral en seguros de cumplimiento a favor de entidades públicas.

\section{A. Pronunciamientos que niegan eficacia al pacto arbitral en contratos de seguro de responsabilidad civil}

Como se señaló en los apartes precedentes, a pesar de parecer clara la regla de incompetencia de la justicia ordinaria para conocer de conflictos nacidos en relaciones contractuales en las que las partes acordaron dirimir sus controversias ante un tribunal de arbitramento, citaré algunas decisiones judiciales en que con ocasión de excepción previa fundada en la existencia de pacto arbitral presentada por compañía aseguradora citada vía llamamiento en garantía, jueces han decidido mantener su competencia restándole eficacia al pacto arbitral.

En seguida un resumen de las consideraciones jurídicas por las cuales tales decisiones judiciales restaron eficacia al pacto arbitral.

I) Auto de 05 de abril de 2017 dictada por el Tribunal Administrativo de Tunja en el expediente 2014-00203-01, MP. Oscar Granados Naranjo.

Se trata de un proceso de reparación directa por falla en el servicio en la prestación de servicios médicos presentado contra una Empresa Social del Estado, en que se llamó en garantía a una compañía aseguradora por cuenta de una póliza de responsabilidad civil. El Tribunal revocó auto del Juzgado administrativo que había desvinculado a la aseguradora ante la excepción previa

10 Sentencia de la Sala de Casación Civil del 1º de julio de 2009 (exp. 11001-3103-039-200000310-01) 
de compromiso o cláusula compromisoria, manteniendo la vinculación de la aseguradora, con base en las siguientes consideraciones.

"Como se concluye de las providencias antes citadas, la cláusula compromisoria pactada en el marco de un contrato de seguro no tiene la virtualidad de enervar el llamamiento en garantía que en el marco de un proceso de reparación directa realice la entidad demandada respecto de la compañia de seguros, particularmente porque:

I), En el medio de control de reparación directa. Lo que se está discutiendo es la presunta responsabilidad civil extracontractual de la demandada imputada por un tercero (demandante), el cual es ajeno al contrato de seguros, II ) la cláusula compromisoria se pactó para dirimir las controversias suscitadas entre las partes del contrato, esto es la aseguradora y el asegurado, III ) el aspecto que sustrajeron del conocimiento de la jurisdicción de lo contencioso administrativo fue la conducta contractual de las partes del contrato de seguro, sin que ello implique que todo aquello atinente a dicho contrato deba ser de competencia de la justicia arbitral, incluida la responsabilidad civil extracontractual."

El Tribunal distingue el objeto del proceso primigenio, la eventual responsabilidad del ente público demandado, con el objeto del proceso conexo en que se analizará la cobertura del contrato de seguro respecto del hecho dañoso, para señalar que dada esta diferencia, el pacto arbitral pactado en su seno no inhibe la competencia de la jurisdicción ordinaria para determinar la existencia de tal responsabilidad patrimonial del Estado.

No es clara la decisión, sin embargo, en si la decisión que mantiene la competencia a pesar de la excepción previa niega toda eficacia al pacto arbitral, o si en el momento de analizar la relación entre llamante y aseguradora se estudiarán sus efectos.

II) Auto 2 de octubre de 2003, Consejo de Estado Sección 4ª, expediente 199900528 03, MP. Ligia López Diaz

Acción de grupo presentada contra el Banco de la República por deudores del sistema UPAC, en que el BR llamó en garantía a varias aseguradoras con base en póliza global bancaria para responder por eventuales condenas fundadas en responsabilidad extracontractual nacida por su actividad regulatoria. Fue aceptado el llamamiento y negada la excepción previa de cláusula compromisoria bajo el argumento de que ese aspecto sólo podría revisarse en la sentencia de fondo, no en la etapa de admisión de la demanda e integración del contradictorio, así:

"Si se llegare a producir una sentencia que condene al Banco de la República a pagar indemnizaciones a los usuarios del UPAC, el demandado podría, 
La eficacia del pacto arbitral en algunos contratos de seguro

bajo el amparo del contrato de seguro, hacer efectiva la póliza y solicitar la compensación por los pagos efectuados a los terceros reclamantes.

El alcance de la póliza y la responsabilidad concreta de las compañías aseguradoras, es una decisión que corresponderá al fallo definitivo, pero en este momento, para la Sala existe la relación contractual entre el demandado y las aseguradoras, las cuales podrían verse afectadas con la decisión final en la presente acción de grupo.

La discusión de fondo de si la póliza ampara tales riesgos o de si aquella estaba vigente, implica una decisión no propia de esta etapa procesal. En efecto, basta con la existencia de una relación contractual o legal entre llamante y llamado que haga pensar a primera vista que existe una garantía que permitiría exigir la indemnización de perjuicios o el reembolso total o parcial del pago que tuviere que hacerse como resultado de una condena."

En esta decisión el Consejo de Estado defirió a la sentencia de fondo en análisis de la relación sustancial entre el ente público llamante y su asegurador, sin que aparezca de tajo negada la eficacia del pacto arbitral. Si se llegase en la decisión final a considerar la incompetencia de la jurisdicción para revisar la relación sustancial traída al proceso en virtud del llamamiento, se podría llegar a considerar la incompetencia de la misma.

III) Auto de 28 de junio de 2017 del Juzgado 9 administrativo Barranquilla, expediente 2015-00211.

Proceso de reparación directa por falla en el servicio en la prestación de servicios médicos presentado contra una Institución Prestadora de servicios de Salud, en que se llamó en garantía a una compañía aseguradora por cuenta de una póliza de responsabilidad civil. El juzgado negó la excepción previa de compromiso o cláusula compromisoria, manteniendo la vinculación de la aseguradora, con base en las siguientes consideraciones.

"Revisadas las cláusulas de las pólizas de responsabilidad anexadas al expediente, se observa que lo señalado se refiere a las controversias que puedan surgir con ocasión de la celebración, ejecución o terminación del contrato de seguros entre el asegurado y P.... compañía de seguros, y en nada tiene que ver con las eventualidades aseguradas y las reclamaciones que se originen del aseguramiento."

El juez de instancia funda la decisión en una dicotomía, equivocada, de normas que regulan la celebración, ejecución o terminación del contrato de seguros, con las que determinan si ha acaecido la condición de la cual pende su obligación de indemnizar por los riesgos trasladados. La principal controversia en relación con contratos de seguros, al amparo de lo previsto e el artículo 
1077 del Código de Comercio, gravita o sobre la exigibilidad de la obligación condicional asumida por la aseguradora o sobre la cuantía de su obligación.

VI) Auto de 27 de octubre de 2017 del Tribunal Administrativo del Atlántico dentro del expediente 2015-00265-01C

Proceso de reparación directa por falla en el servicio en la prestación de servicios médicos presentado contra una Institución Prestadora de servicios de Salud, en que se llamó en garantía a una compañía aseguradora por cuenta de una póliza de responsabilidad civil. El juzgado aceptó la excepción previa de compromiso o cláusula compromisoria, decisión que recurrida por el llamante en garantía fue revocada por el Tribunal ordenando mantener la vinculación de la aseguradora, con base en las siguientes consideraciones.

"Es de anotar que la cláusula compromisoria pactada en el marco de un contrato de seguro no tiene la posibilidad de enervar el llamamiento en garantía que en el marco de un proceso de reparación directa realice la entidad demandada, en este caso la XXXX, respecto a la compañía de seguros.

(...)

Como las pretensiones del proceso están encaminadas a endilgar una presunta responsabilidad a XXXX, mas no al presunto incumplimiento del contrato de seguro suscrito entre la entidad demandada y el llamado en garantía, la cláusula compromisoria existente en el contrato de seguro no excluye la competencia del juez administrativo para conocer del llamamiento en garantía."

En esta decisión se niega toda eficacia al pacto arbitral, reservándose el Juez de instancia la competencia para resolver tanto la controversia original sobre la existencia de un daño antijurídico indemnizable, como su eventual traslado a la compañía aseguradora en virtud del contrato de seguro vinculado al proceso consecuencia del llamamiento propuesto por el ente público demandado.

a. Examen de la ratio decidendi en las decisiones que negaron eficacia al pacto arbitral.

De los pronunciamientos judiciales comentados que negaron eficacia al pacto arbitral con ocasión de un llamamiento en garantía, tres argumentos basales se pueden extraer como fundamento de las decisiones.

1. La existencia de la cláusula arbitral no inhibe ab initio la competencia del juez ordinario para revisar la existencia de la relación contractual de que da cuenta el contrato de seguro, postergándose la decisión de fondo a la resolución final del proceso en la sentencia de instancia.

Se considera que esta posición desconoce que a través del llamamiento se busca eficacia, economía y celeridad en las decisiones judiciales, teniendo 
en cuenta que en la sentencia, al momento de analizar la relación sustancial entre llamante y aseguradora, bien podría concluirse que el juez ordinario no tiene competencia por la existencia de pacto arbitral.

2. El pacto arbitral habilita la competencia extraordinaria sólo para asuntos contractuales directos entre tomador y compañía aseguradora, no quedando en consecuencia comprendido dentro de aquel la eventual responsabilidad frente a terceros.

Posición equivocada que desconoce las normas que gobiernan el contrato de seguro y su propósito económico, el traslado de riesgos del asegurado a la compañía aseguradora.

3. La existencia de compromiso o cláusula compromisoria no excluye la competencia especial del juez contencioso para estudiar las pretensiones de reparación directa, por no versar el litigio principal sobre el incumplimiento del contrato de seguro.

Esta decisión niega toda eficacia al pacto arbitral contenido en contratos de seguro de responsabilidad civil, que bien podría justificarse en principios de eficacia, economía y celeridad, pero que al no justificarse en ellas impide un mejor análisis de la razón en que se funda.

\section{B. Pronunciamientos que reconocen eficacia al pacto arbitral en contratos de seguro de responsabilidad civil}

Como se señaló con anterioridad, las más de las veces en que se debate la eficacia del pacto arbitral como excepción de incompetencia frente al llamamiento en garantía que se le formula a una aseguradora, la jurisdicción ordinaria reconoce su incompetencia dando plena eficacia al pacto arbitral.

En seguida un resumen de las principales consideraciones jurídicas por las cuales tales decisiones judiciales reconocieron eficacia al pacto arbitral, reiterando que por ser las que con mayor frecuencia se producen sólo se tratarán algunas que con relevancia recogen las razones para ello.

I) Auto de 1 de julio de 2007, Expediente 1999-01068 de la Sección Tercera del Consejo de Estado, MP. RUTH STELLA CORREA PALACIO

Extracto citado por el Consejo de Estado en auto que declaró nulidad de todo lo actuado de 7 de marzo de 2012, en el marco de una acción contractual en que en el convenio interadministrativo se había previsto cláusula compromisoria, en que se reiteró jurisprudencia citada.

"De acuerdo con el decreto 1818 de 1998 -Estatuto de Mecanismos Alternativos de Solución de Conflictos - artículo 118-, la cláusula compromisoria es un 
pacto contenido en un contrato, en virtud del cual los contratantes acuerdan someter las eventuales diferencias que puedan surgir con ocasión de éste, a la decisión de un Tribunal de Arbitramento. En virtud de este pacto las partes comprometidas en él, en uso de la libre autonomía de la voluntad, deciden declinar la jurisdicción institucional del Estado para en su lugar someter la decisión del conflicto que pueda presentarse entre ellas, a la decisión de árbitros, particulares investidos transitoriamente de la función de administrar justicia, en los términos del artículo 116 superior; así, cualquier conflicto sometido a la cláusula compromisoria, escapa a la decisión de los jueces institucionales del Estado, a menos que las partes decidan derogar tal cláusula, de manera expresa, o tácitamente al aceptar sin réplica la citación que cualquiera de ellas haga a la otra, ante los jueces institucionales del Estado, situación que no se da en este evento, cuando una de las partes reclama su aplicación. Esta Corporación ha establecido en reiterados pronunciamientos que la existencia de la cláusula compromisoria excluye de competencia a la Jurisdicción Contenciosa, por lo que, en el caso concreto tratándose de una vicisitud que surge con ocasión de la póliza de seguro, ésta debe ser dirimida por árbitros, sin que haya lugar bajo el amparo de la figura del llamamiento en garantía, a que esta jurisdicción dirima contiendas que tienen como fuente el contrato de seguros en el que se pactó la cláusula compromisoria."

Ante la alegación de incompetencia por pacto arbitral entre llamante y aseguradora, debe dársele plena validez en respeto del principio de habilitación al querer de las partes de sustraer del conocimiento de la justicia ordinaria su conflicto. No hay modulación de esta consecuencia.

II) Auto de 29 de febrero de 2008 de la Sección Tercera del CONSEJO DE ESTADO En el expediente 200100185-04, MP. Mauricio Fajardo

Auto dictado al revisar apelación de auto que aceptó llamamiento en garantía en proceso de reparación directa por cuenta de póliza de seguro de responsabilidad civil.

Así pues, al pactarse una cláusula compromisoria dentro del contrato de seguro suscrito entra la parte demandante y las sociedades llamadas en garantía, cualquier controversia que pueda suscitarse en razón de dicho acuerdo debe ser resuelta por un tribunal de arbitramento, razón por la cual, esta jurisdicción no puede emitir pronunciamiento alguno acerca de ellas, como quiera que la existencia de esta cláusula excluyó su competencia, según se ha indicado.

En consecuencia, en aplicación del numeral $1^{\circ}$ del artículo 140 del Código de Procedimiento Civil, se declarará la nulidad de todo lo actuado por falta de jurisdicción, desde el auto del 14 de noviembre de 2001 en todo lo que tenga relación con el llamamiento en garantía de La Previsora S.A. Compañia de 
Seguros y la Aseguradora Colseguros S.A., en virtud de la póliza 1000134, lo cual, a su vez, releva al despacho del estudio del recurso de apelación formulado por La Previsora S.A., contra el auto que negó una prueba.

Toda controversia nacida con ocasión y por cuenta del contrato de seguro en que se pactó cláusula compromisoria debe ser conocida por la justicia arbitral, sin importar su objeto o naturaleza. El Consejo de Estado reconoce que en los asuntos en que no se debate la legalidad de actos administrativos y existe pato arbitral, la jurisdicción ordinaria no es en la que debe resolverse dicho conflicto.

b. Examen de la ratio decidendi en las decisiones que reconocen plena eficacia al pacto arbitral

De los pronunciamientos judiciales comentados que reconocieron plena eficacia al pacto arbitral con ocasión de un llamamiento en garantía, un argumento fundamental se puede extraer como fundamento de la decisión:

1. El pacto arbitral, mientras no se haya anulado, implica la incompetencia absoluta de la jurisdicción ordinaria para revisar los conflictos jurisdiccionales cobijados por él.

\section{El pacto arbitral y la declaración de incumplimiento de contrato estatal en relación con la garantía única de cumplimiento}

Limitado el objeto de este estudio al análisis de la eficacia del pacto arbitral en algunos contratos de seguro, que por supuesto se vería desbordado frente al complejo tema de la facultad exorbitante que tienen las entidades públicas para declarar incumplimientos contractuales y ordenar la caducidad de contratos sometidos a Ley 80, partiendo de la base de que es clara y reiterada la jurisprudencia que reconoce a las entidades públicas la capacidad plena de declarar incumplimientos, y con base en ello tener por acaecido el riesgo asegurado en pólizas de cumplimiento de contratos públicos para consecuentemente considerarlas habilitadas para ejecutar las obligaciones contenidas en dichas pólizas al amparo de lo previsto en el 68 del CCA, hoy 99 del CPACA, en este aparte alguna breve reflexión sobre el asunto que interesa.

Como proemio al análisis de la cuestión objeto de este escrito, vale la pena recordar cómo la jurisdicción contenciosa ha calificado a la garantía única de cumplimiento de que trata la Ley 80 como un verdadero contrato de seguro pero con una regulación especial de naturaleza pública, o de doble naturaleza comercial y administrativa, para señalar, entre otras, que ciertas reglas del Código de Comercio como la que impone al beneficiario del pago de la indem- 
nización el deber de acreditar ante el asegurador tanto la ocurrencia del siniestro como la cuantía de la pérdida, o la que le permite al asegurador excusarse del cumplimiento de su prestación mediante objeción seria y fundada ante una reclamación, no operan en este tipo especial de seguro.

Dijo la Sección Tercera del Consejo de Estado en sentencia de 19 de febrero de 2009 dentro del radicado 2000-01720-01(24609) lo siguiente:

"Sobre el particular, resulta necesario señalar que los contratos de seguro que se originan para garantizar el cumplimiento de un contrato estatal, si bien están regidos por las normas de derecho privado y particularmente por las disposiciones del Código de Comercio, también están sujetos, en determinados aspectos, a normas de derecho público.

En efecto, el estatuto de contratación estatal se ocupó de regular los aspectos generales y fundamentales de los contratos de seguro que se celebren para garantizar el cumplimiento de los contratos estatales, lo cual evidencia que los mismos también se encuentran sometidos a sus disposiciones, normatividad especial que, al menos, da lugar a la configuración de un régimen legal de carácter mixto que en modo alguno puede tildarse como integrado exclusivamente por normas de derecho privado, tal como lo reflejan el contenido del numeral 4 del artículo 5o, el inciso final el artículo 18, el numeral 19 del artículo 25, el inciso 2 del artículo 41 y el inciso final del artículo 60, todas esas disposiciones de la Ley 80, normas de orden público y, por ende, de obligatorio cumplimiento tanto para las entidades estatales contratantes como para los contratistas particulares, quienes no podrán negociar sobre su contenido ni eludir su observancia.

Así, por ejemplo, los efectos que se derivan de las cláusulas excepcionales de terminación, modificación e interpretación unilaterales, caducidad y reversión, previstas, consagradas y reguladas en los artículos 14, 15, 16, 17, 18 y 19 de la Ley 80, tan propias y específicas de determinados contratos estatales, gravitan permanentemente sobre los contratos de seguros que se celebren para garantizar el cumplimiento de los vínculos obligacionales que los contienen y generan, al punto que por expresa disposición legal, la declaratoria de caducidad administrativa de un contrato estatal "... será constitutiva del siniestro de incumplimiento" (artículo 18 Ley 80), efecto éste que naturalmente se proyecta sólo en relación con el correspondiente contrato de seguro de cumplimiento."

Es claro el Consejo de Estado al determinar con claridad que en contratos de cumplimiento a favor de entidades públicas, son estas plenamente competentes, en ejercicio de sus potestades públicas, para declarar tanto la ocurrencia del siniestro como detonante de la obligación condicional de la aseguradora, como para señalar la cuantía de la pérdida. Obvio está sin cercenar la posibilidad 
La eficacia del pacto arbitral en algunos contratos de seguro

de discutir ante el Contencioso la legalidad de tales decisiones a través de los medios de control de la actuación administrativa.

Respecto de la plena competencia sobre declaratoria de incumplimiento y consecuente capacidad para cobrar, incluso coactivamente, las garantías contractuales ha dicho el Consejo de Estado ${ }^{11}$ :

"Mediante la lectura del precitado artículo se deduce claramente que las entidades públicas pueden hacer efectivas las garantías constituidas a su favor por el contratista, mediante un acto administrativo que bien puede ser aquel en el que previamente se declare el incumplimiento.

(...)

"La situación se torna diferente en tratándose de garantías de cumplimiento constituidas en favor de entidades públicas para garantizar el cumplimiento de las obligaciones contraídas por el contratista, así que el citado artículo 1077 no es de aplicación estricta, puesto que no es ante la compañía aseguradora que el asegurado o beneficiario de la póliza -entidad estatal-discute la existencia del siniestro y el monto del perjuicio o daño causado, tal como quedó ampliamente expuesto en el acápite anterior, sino que la entidad pública asegurada a términos del artículo 68, numerales 4) y 5) del C.C.A., tiene la potestad de declarar unilateralmente la existencia de la obligación derivada del contrato de seguro, declaratoria que necesariamente involucra o versa sobre la ocurrencia del siniestro y la cuantía del daño, ya que de lo contrario no surge la obligación a cargo de la aseguradora, pues como ya se anotó, para que ello ocurra, según lo dispone el artículo 1077 del C. de Co, deberá establecerse la ocurrencia del siniestro y la cuantía del daño, en tratándose de seguros de daños."

La misma Corporación, reiterando la plena competencia de las entidades regidas por Ley 80 para declarar la ocurrencia de los riesgos cubiertos por la garantía única, no sólo a través de la declaratoria de caducidad que está expresamente prevista en el artículo 16 del estatuto de contratación, sino de los otros amparos extendidos como el de incumplimiento, señalando que incluso es posible la declaratoria en sede administrativa del acaecimiento del riesgo cubierto por el amparo de estabilidad de la obra que el propio Consejo bautiza como obligación post contractual.

En este sentido se ha pronunciado el Alto Tribunal en sentencia en que fue ponente el Dr. Mauricio Fajardo Gómez de 24 de julio de 2013 dentro del radicado 2001005101(27.505).

11 CONSEJO DE ESTADO SECCIÓN TERCERASentencia del 13 de mayo de 2009. Radicación 25000-2331-000-11430. C.P. Ramiro Saavedra Becerra. 
"Ahora bien, en relación con la exigibilidad de la garantía de cumplimiento que no se encuentra en el escenario de la declaración de caducidad del contrato -como sucede con la garantía de estabilidad de la obra cuyo riesgo se materializa después de que el contratista ha cumplido con la entrega de la obra y se la ha recibido a satisfacción- la jurisprudencia del Consejo de Estado ha encontrado que dicha competencia de la entidad estatal contratante encuentra consagración o apoyo legal en el artículo 68 del Código Contencioso Administrativo, toda vez que la norma en cita atribuye a la entidad pública la facultad de declarar la exigibilidad de las obligaciones amparadas con las pólizas de seguro y demás garantías que otorguen los contratistas ${ }^{12}$, con el fin de integrar el título ejecutivo para el cobro, sin perjuicio de advertir que en todo caso la expedición del respectivo acto administrativo debe respetar los derechos y acciones de los contratistas $y$ de las compañías aseguradoras, tanto en la actuación que precede a la declaratoria del siniestro, como en la expedición de los actos administrativos que se emitan en ejercicio de la mencionada atribución."

Es decir, en tratándose de seguros a favor de entidades públicas consecuencia de la actividad contractual, bien declarando el incumplimiento del contratista o la caducidad del contrato, incluso la ocurrencia directa del riesgo cubierto de inestabilidad de la obra una vez entregada al Estado, está capacitada la entidad asegurada para declarar la ocurrencia del siniestro y la cuantía de la pérdida, con lo cual es ejecutable, incluso por vía coactiva, la obligación de la aseguradora cumplidos los requisitos del artículo 1077 del Código de Comercio por acto administrativo.

Ahora bien, clara como está la influencia de la normatividad pública en el marco del contrato de seguro de cumplimiento a favor de entidades estatales de que habla la Ley 80 de 1993, y los efectos de que ello se desprenden, cabe preguntarse si es posible introducir en las condiciones particulares o generales de dichos contratos de seguro una cláusula arbitral, y el efecto que se produce de ser así en el ámbito de competencia de la propia entidad, del eventual tribunal de arbitramento y de la jurisdicción contencioso administrativa para resolver controversias sobre estos extremos.

La primera pregunta encuentra respuesta positiva a la luz de múltiples pronunciamientos tanto de la Corte Constitucional como del Consejo de Estado, instancia en la que se ha dictado incluso sentencia de unificación respecto de la

12 Artículo 68. Definición de obligaciones a favor del Estado que prestan mérito ejecutivo: (...)

"Las demás garantías que a favor de las entidades públicas se presten por cualquier concepto, las cuales se integrarán con el acto administrativo ejecutoriado que declare tal obligación". 
La eficacia del pacto arbitral en algunos contratos de seguro

irrenunciabilidad a la jurisdicción arbitral una vez incluida en legal forma en un contrato estatal, que se ha dicho puede preverse incluso desde los pliegos de condiciones que son la ley particular de cada contrato tal y como se consignó en auto de 18 de abril de 2013 dentro del expediente 17.859 con ponencia del Dr. Carlos Alberto Zambrano Barrera, que por supuesto se puede extender a las condiciones particulares o generales de una garantía única de cumplimiento a la sombra de lo previsto en el parágrafo del artículo 1047 del C. de Co., tal y como fuera modificado por la Ley 389 de 1997.

Para revisar el efecto del pacto arbitral contenido en una garantía única de cumplimiento a favor de entidades estatales es importante revisar qué ha dicho el Consejo de Estado al respecto, por supuesto a la luz de lo ya señalado en relación con la competencia indiscutida que tienen los entes públicos para declarar la ocurrencia del siniestro y cobrar, incluso coactivamente, a través del que se ha reconocido como título de ejecución complejo -acto administrativo, póliza de cumplimiento y contrato estatal garantizado- la indemnización a cargo de la aseguradora, para presentar las conclusiones correspondientes que desde ya se avizoran.

En ese sentido vale la pena recordar lo señalado en sentencia del 13 de mayo de 2009 dentro del radicado 25000-2331-000-11430 con ponencia del magistrado Ramiro Saavedra Becerra, donde se revisó el tema.

"Se precisa en primer lugar que, aún cuando estuviese comprobada la existencia del pacto arbitral, esta circunstancia no excluye la facultad que le asigna la ley a las entidades públicas para declarar ocurrido el siniestro amparado por la póliza de seguro.

(...).

Ahora, en cuanto a lo expuesto por la parte actora para sustentar la incompetencia material de la entidad, la Sala advierte que la circunstancia de que el contrato estatal contenga una cláusula compromisoria, no conduce a considerar excluidas las competencias y facultades que la ley le atribuye a una entidad pública contratante.

La cláusula arbitral produce el efecto de que, en el evento de suscitarse un litigio que deba dirimirse ante un juez, las partes ejerciten la correspondiente acción ante un tribunal de arbitramento legalmente constituido, a menos que se renuncie tácita o expresamente a ella.

En el caso concreto, como pasa a explicarse en el capítulo siguiente, la entidad pública, al considerar incumplido el contrato de transporte por el faltante de unos valores, no tenía que acudir ante el juez del contrato estatal para hacer efectiva la póliza, pues contaba con facultades previstas en la ley, para declarar la ocurrencia del siniestro y hacer efectiva la póliza respectiva. 
Se precisa además que, como el presente litigio gira en torno a la legalidad del acto administrativo por medio del cual la entidad declaró ocurrido el incumplimiento del contratista e hizo efectiva la garantía única de cumplimiento, no resultaba procedente adelantar este proceso ante un Tribunal de arbitramento, porque, conforme lo ha manifestado reiteradamente la Sala, los árbitros carecen de competencia para juzgar la legalidad de un acto administrativo, por tratarse de una materia que no es transigible."

A la luz de tal pronunciamiento, en conjunto con otros ya citados y que reconocen sin dubitación la competencia administrativa de los entes públicos contratantes para señalar, con plenos efectos declarativos de siniestro como detonante de la obligación subordinada a su ocurrencia la caducidad, el incumplimiento o defectos constructivos asegurados bajo el amparo de estabilidad, se impone la conclusión de que en tales eventos el pacto arbitral no es oponible como causal de incompetencia y por tanto frente a tales eventos el convenio sobre arbitraje no produce efectos.

Más aún si, como recuerda el Consejo de Estado en la sentencia últimamente citada, hay contundente jurisprudencia que ha limitado la competencia de la justicia arbitral para pronunciarse sobre la legalidad de los actos administrativos bajo la consideración de que ellos sólo pueden ser, por mandato constitucional, revisados por la jurisdicción contencioso administrativa ${ }^{13}$, al ser manifestación de poder soberano no transigible y por tanto excluida de la posibilidad de ser revisados por la justicia arbitral.

Ahora bien, si se previó en una garantía única de cumplimiento estatal una cláusula compromisoria esta sigue manteniendo plenos efectos para todos aquellos aspectos en conflicto que no se relacionen con el juzgamiento de la legalidad de actos administrativos dictados por la entidad pública beneficiaria, como lo ha recordado recientemente el Consejo de Estado en auto de 15 de mayo de 2014 dictado por la Magistrada María Elizabeth García en el radicado 200600131 02, en donde se dijo:

"De manera que, no son de recibos los argumentos de XXX con los cuales pretende que se revoque el auto que admitió su llamamiento en garantía, por cuanto, como fue explicado en la providencia transcrita, la controversia gira en torno a la legalidad de los actos administrativos expedidos por YYY y no al presunto incumplimiento del contrato de seguro, por lo que es a la Jurisdicción Contencioso Administrativa a quien corresponde dirimir el conflicto"

13 Sentencia C-1436 de 2000 de la Corte Constitucional, MP. Alfredo Beltrán, y del Consejo de Estado, entre otras, sentencia de 9 de octubre de 2003, ponente GERMÁN RODRÍGUEZ VILLAMIZAR rad. 1994-09988-01(16718), 
La eficacia del pacto arbitral en algunos contratos de seguro

Claro entonces queda que la competencia arbitral se mantendrá en todos los contratos de seguro de cumplimiento a favor de entidades públicas, siempre y cuando no se intente someter a su conocimiento el juzgamiento sobre la legalidad de actos administrativos dictados por la entidad pública asegurada, siendo del resorte exclusivo de la jurisdicción contenciosa su control jurisdiccional.

\section{Conclusiones}

Habiéndose dirigido este escrito a revisar la eficacia del pacto arbitral contenido en contratos de seguro, en especial frente a seguros de responsabilidad civil y luego en contratos de seguro de cumplimiento en favor de entidades estatales, las conclusiones sobre la revisión de los fundamentos de las decisiones analizadas se presentarán en el mismo orden. Quedan asuntos que bien podrían considerarse en futura oportunidad como el relacionado con la eficacia de la habilitación de la jurisdicción arbitral cuando el pacto se incluye en clausulados preestablecidos por una de las partes.

Sin perjuicio de tal metodología la primera gran y general conclusión es que en los contratos de seguro el pacto arbitral es plenamente eficaz, y ante su existencia el juez ordinario debe declarar su propia incompetencia, quedando afectado por nulidad insaneable lo actuado con posterioridad al reconocimiento de la existencia del pacto conforme se señaló por la Corte Suprema de Justicia en jurisprudencia citada.

Frente al propósito de este escrito, las conclusiones sobre la eficacia del pacto arbitral en determinados contratos de seguro se presentarán siguiendo el orden del escrito, primero frente al contrato de responsabilidad civil a la luz de las decisiones que negaron, por un lado, o que reconocieron plena eficacia, por el otro, al pacto arbitral; luego las que se encontraron en relación con la eficacia del pacto en el contrato de cumplimiento a favor de entidades públicas.

a. Conclusiones en materia de seguro de responsabilidad civil

De las razones principales en que se fundan los pronunciamientos que niegan eficacia, procesal o material, al pacto arbitral cuando se opone la excepción de incompetencia durante el trámite de un llamamiento en garantía, unos breves comentarios a la luz de los pronunciamientos que si le reconocen eficacia, anticipando desde ya nuestra posición alineada con la interpretación, mayoritaria aun, que cede la jurisdicción ante la particular cuando aparece convenida una cláusula arbitral:

i.) Deferir la decisión de la incompetencia a la sentencia de fondo:

Este argumento, en mi opinión, desdibuja la razón de eficacia y economía procesal en que se sustenta la naturaleza de previa de la excepción de pacto arbitral, si ella se formuló en tiempo. 
Si el pacto arbitral existe la incompetencia de la justicia ordinaria viene dada por la Ley y nada justifica que tal decisión se adopte luego de tramitado íntegramente el proceso, mas cuando en tal momento, dados los pronunciamientos analizados, ninguna razón se opondría a reconocerle eficacia y en consecuencia a negar la competencia para resolver el conflicto objeto del llamamiento que equivaldría a sentencia inhibitoria en relación con el llamamiento, que supone incumplimiento de uno de los deberes del juez ;

ii) Distinguir entre asuntos del contrato de seguros y de los efectos de cobertura para negar eficacia del pacto arbitral.

Dicha argumentación se funda en una distinción que no existe en la ley respecto de lo que se llama por el juez "aspectos contractuales" del seguro entre tomador y asegurado, que parecieran ser aquellos relacionados con la formación del consentimiento y la eficacia obligacional del contrato, y los relativos a la prueba del nacimiento, extensión y cumplimiento de la obligación indemnizatoria condicionalmente asumida por el asegurador, que no sólo es equivocada conceptualmente sino que además desconoce la plena eficacia al pacto arbitral en la forma tajante y concluyente que se le ha reconocido por nuestras altas corporaciones de justicia.

En consecuencia, considerando equivocados los fundamentos de las decisiones que niegan eficacia al pacto arbitral propuesta excepción previa de compromiso o cláusula compromisoria, tanto en el trámite de un llamamiento en garantía como en el caso de demanda del beneficiario directo en contratos de responsabilidad civil, al estar convenido pacto arbitral se determina con claridad la incompetencia de la justicia ordinaria, y por ello los asuntos en la cláusula comprendidos, al haber sido reservados para el conocimiento exclusivo de la justicia arbitral, quedan por fuera del conocimiento de la justicia ordinaria que siempre resultaría incompetente.

Esto es, propuesta excepción de compromiso o cláusula compromisoria y verificada su existencia, bien siendo las aseguradoras demandadas directamente o bien por que fueron convocadas al proceso por llamamiento en garantía, el juez ordinario debe reconocer su propia incompetencia siendo plenamente eficaz el pacto arbitral, y por ello determinada en forma exclusiva la competencia de la justicia arbitral para definir estas controversias.

b. Conclusiones en materia de seguro de cumplimiento estatal.

En tratándose de seguros de cumplimiento a favor de entidades estatales públicos es clara la competencia exclusiva que tiene la jurisdicción contencioso administrativa para revisar la legalidad de los actos administrativos contractuales expedidos en ejercicio del poder de imperium, sin perjuicio de lo cual y cuando la controversia verse sobre asuntos en que las partes del contrato están en igualdad 
de condiciones y se trate de asuntos transigibles, si las partes acordaron una cláusula arbitral la competencia exclusiva para conocer de tales controversias es de la justicia arbitral.

Esto es que si se trata de revisar la legalidad de las decisiones administrativas que declararon el siniestro de caducidad, de incumplimiento, incluso de estabilidad de la obra ya liquidado el contrato estatal asegurado, o la cuantía de la obligación resarcitoria por cuenta de la póliza de seguro, la jurisdicción contencioso administrativa es la única competente y frente a tales asuntos el pacto arbitral es ineficaz; en tanto que si se trata de revisar otros asuntos distintos, frente a la existencia de pacto arbitral la justicia ordinaria debe reconocer su incompetencia dando plena eficacia al querer de las partes que habilitaron a la arbitral para la definición de sus controversias.

\section{Bibliografía}

\section{Doctrina}

BENETTI SALGAR, Julio “El arbitraje en el Derecho colombiano." Ed Temis, Bogotá, Colombia. 1994.

LÓPEZ BLANCO, Hernán Fabio. "Comentarios al Contrato de Seguro". Dupré Editores, Bogotá Colombia. 2a ${ }^{\mathrm{a}}$. Edición, 1993.

MANCIAUX, Sébastien. "El orden público y el arbitraje." Editorial Universidad del Rosario, Bogotá, Colombia. 2017.

RACINE, Jean Baptiste. Las normas que estructuran el orden público en el arbitraje comercial internacional. En: "El orden público y el arbitraje." Editorial Universidad del Rosario, Bogotá, Colombia. 2017.

RAMÍREZ GÓMEZ, Jorge Alberto. La vinculación de sujetos no signatarios a los efectos del pacto arbitral. Ed. Universidad Externado de Colombia, Bogotá, Colombia. 2017.

\section{Jurisprudencia}

COLOMBIA, CONSEJO DE ESTADO. Sentencia de 9 de octubre de 2003. C.P. GERMÁN RODRÍGUEZ VILLAMIZAR. Rad. 1994-09988-01(16718).

COLOMBIA, CORTE CONSTITUCIONAL. Sentencia C-170/2014. MP. Alberto Rojas Ríos, 19 de marzo de 2014.

COLOMBIA, CORTE CONSTITUCIONAL. Sentencia C-1436 de 2000. MP. Alfredo Beltrán. 


\section{Dionisio Araujo Angulo}

COLOMBIA, CORTE SUPREMA DE JUSTICIA. Sentencia de la Sala de Casación Civil del 1º de julio de 2009 (exp. 11001-3103-039-2000-00310-01).

CONSEJO DE ESTADO SECCIÓN TERCERAS. Sentencia del 13 de mayo de 2009. Radicación 25000-2331-000-11430. C.P. Ramiro Saavedra Becerra.

CORTE SUPREMA DE JUSTICIA, SALA DE CASACIÓN CIVIL, Sentencia de 9 de mayo de 2017, Expediente $\mathrm{N}^{\circ}$ 11001-31-03-019-2008-00247-01. MP. Margarita Cabello Blanco.

CORTE SUPREMA DE JUSTICIA, SALA DE CASACIÓN CIVIL. Expediente SC5885-2016, sentencia del 6 de mayo de 2016, MP. Luis Armando Tolosa Villabona.

CORTE SUPREMA DE JUSTICIA, SALA DE CASACIÓN CIVIL. Sentencia de 15 de diciembre de 2006 dentro del expediente No. 52001-31-03-004-200000276-01. MP. Jaime Alberto Arrubla Paucar. 